\title{
Why children have aggressive behaviors
}

\section{— The Influence Factor of the Gene, Parents, Peer Group and Social Media}

\section{Shikun Su}

\author{
Department of Psychology, Franklin and Marshall College, 415 Harrisburg Ave., Lancaster, USA \\ ssu@fandm.edu
}

Keywords: Aggressive behaviors, children, biological factors, sociological factors

\begin{abstract}
Aggressive behaviors are common among kindergarten children to adolescents. Children may start aggressive behaviors at a very small age, and children who display more aggressive behaviors tend to be more violent when they grow up. So, it is important to discuss aggressive behaviors of children because it will predict their future aggressive behaviors. It is also important to know the factors that could influence the aggressive behaviors of children because it will help to solve this problem in order to bring a positive influence on both individuals and society. In this paper, we conclude the influential factors of children's aggressive behavior, including biological and sociological. More importantly, we discuss how these factors work and how they interacted with each other.
\end{abstract}

\section{Introduction}

Aggressive behaviors can be defined as behavior that is aimed at harming or injuring another person or persons. Children's aggression can be divided into explicit aggression and implicit aggression. Specifically, these two types of aggression can be divided into four forms: physical aggression, which refers to use of body or weapons to show hostility, such as fighting; Verbal aggression refers to through the direct use of hurtful words, including verbal insults and threats, swearing and quarrels. Social aggression, which means adopting concealed method to destruct someone's social relationship with others, including social isolation, betrayal of trust of others; Direct relationship aggressive, which means destroying the relationship with others by face to face, including not to talk to someone, deliberately ignore someone, threatening to pull out the friendship relations, directly tell someone group activities do not welcome him or her. There are two kinds of aggressive children among all children: reactive aggression and proactive aggression. Reactive aggressive children usually display a hostile defensive response to a prior provocation and proactive aggressive children usually expect the positive outcomes from doing the aggressive behaviors [1].

Aggressive behaviors are common among from kindergarten children to adolescents. There are different reasons for displaying aggressive behaviors among kindergarten children and adolescents [2-3]. Most studies now focus on adolescents [4-6]. This may because the adolescents usually elicit more aggressive behaviors than children [7]. Even though, these aggressive behaviors can start at a very young age. For example, it is well known that almost all children exhibit kinds of aggressive behaviors (e.g.: kicking, pulling, biting, pinching) in their first few years of life, and those aggressive behaviors first showed up when children are as early as 6 to 8 months of age [8]. Therefore, it is important to pay attention to the aggressive behaviors of smaller children.

It is important to address the aggressive behavior in children because it is known that aggressive behaviors are associated with school dropout, substance use and criminal activities [2]. It can also predict children's conduct problem in future life [9]. Understanding the factors related to children's aggressive behaviors can reduce the aggressive behaviors or inhibit the development of aggressive behaviors, which have great significance to children's mental health. 


\section{Parenting behavior in children's aggressive behaviors}

Previous research shows that harsh parenting is a reasonable predictor of children's aggressive behavior [10-11]. Especially when parents do corporal punishment to their children, the children who were punished may feel that it is acceptable to be unkind to others. That is the reason the aggressive behaviors form.

Some researchers argue that it is too rough to state harsh or not harsh parenting to understand the effect of parenting behaviors on children's aggressive behaviors. It should be more elaborate to address the 4 kinds of parenting styles: authoritarian parenting (cooler and more directive parenting), authoritative parenting (warmer, more directive parenting), disengaged parenting (cooler, less directive parenting) and permissive parenting (warmer, less directive parenting) [12]. Different parenting styles affect the children's aggressive behaviors differently. For example, children with authoritative parenting often show less aggressive behaviors than children with authoritarian parenting [5]. This may potentially due to authoritarian parenting show less parental warmth, and parental warmth usually predict less aggressive behaviors [13]. Some research also argues that permissive parenting is a predictor of children's aggressive behaviors [14]. This may due to that they are less directive to their children's behaviors and provide fewer instructions.

Different parenting styles will also result in children's proactive aggression or reactive aggression. For example, authoritarian parenting and hostile parenting may promote both proactive aggression and reactive aggression. This is because this parenting style will provide a threatening family environment for children and provide models for children to learn to use aggression. In comparison, permissive parenting related to proactive aggression more because permissive parents give children more autonomy, even in aggressive acts [1].

\section{Peer Influence}

Not only do parenting affect children's aggressive behaviors, but group socialization will also affect their behaviors. For example, the prevalence of bullying problem has been investigated among kindergarten children, school-aged children. One of an important reason for bullying is the peer influence. That is, aggressive kids tend to be friends with aggressive kids and bullying victimized kids. A prosocial kid in an "aggressive kid" group will be influenced by their peers and become aggressive. Victimized children tend to stay alone and lack of friendship, which makes them be easily bullied [6]. In addition, when adolescents get mature, aggressive behaviors such as vandalism is a "cool sign" for them. Acting out those aggressive behaviors is one way for aggressive kids to attract attention and keep their status in class. A good kid may afraid of being excluded by their social groups and become victims of bullying, therefore, they tend to bully others in order to be part of the social group [4].

Even for children at a very small age, peer rejection will influence their behaviors in the future. peer rejection for children under age 5 will lead to more aggressive behaviors among children aged 5-12. The researchers assumed that peer rejection will harm children's psychological health and then those children tend to show aggressive behaviors and harm other kids when they grow up [15].

Therefore, the aggressive behaviors of children could be influenced by other children. Meanwhile, teachers, who play a very important role in the development of children, also have a great influence on children's aggression. As mentioned above, parental warmth will decrease children's aggressive behaviors. Teachers' warmth will do the same thing. Although peer rejection will increase aggressive behaviors, teachers' warmth will decrease the peer rejection to aggressive behaviors. In classes whose teacher show high aversion to aggressive behaviors, peer rejection will increase. Overall, children tend to take teachers' responses as a cue to their behaviors [16].

\section{Genetic influence on aggressive behavior}

Parenting does have an influence on children's aggressive behaviors. Genes may lead to the differences in parenting and children's behaviors. That is, parents' or children's genotype, defined 
as one's genetic makeup, will lead to the differences in parenting styles and children's behaviors. These factors will influence children's aggressive behaviors [17]. For instance, children's genes may determine their phenotype. Then children with different phenotype may elicit different responses from their parents. For example, children instigation is an important predictor of parents' behavior, regardless of the parents of the trait aggression or not. In addition, parents' genes may determine their phenotypes, which interacts with children's phenotype to affect the parenting and the behavior of children. For example, parents with trait aggression are more likely to elicit harsh parenting to their children with children's instigation [18]. And, as mentioned above, harsh parenting may lead to children's aggressive behaviors. Therefore, an aggressive child tends to become more and more aggressive. This is because an aggressive child tends to elicit harsh parenting, which makes them become more aggressive.

Even if harsh parenting or parents with trait aggression will lead to aggressive behaviors, children may bear with different susceptibility in accepting parenting behaviors. That is to say, even under a "bad parenting", some children may still have more prosocial behaviors and less aggressive behaviors. Swedish idiomatic expression divided children into "dandelion" children and "orchid" children. Dandelion children will thrive in either positive or negative experiences. Orchid children are sensitive to both positive and negative experiences. To be more specific, children may bear with certain "plasticity genes", which makes them become dandelion children or orchid children. Those plasticity genes will, in turn, affect children's ability to experience negative emotions. For example, children who born with more 5-HTTP alleles are more likely to accept the bad influence of a bad parenting style. This is because they are more likely to accept negative emotions than children have less 5-HTTP allele. Therefore, harsh parenting styles may affect more to orchid children. Then orchid children may have more aggressive behaviors under the harsh parenting [19].

\section{Media influence}

Media does have some influence on children's aggressive behaviors, especially young children spend a lot of time on violent media. For example, by watching a film, children observe the behaviors and imitate what the characters in films do. Boys tend to imitate more compared with girls [20]. Children who play violent games may make children feel the pleasure of aggressive behaviors and lead to aggressive behaviors in real life [21]. It would be a societal challenge to limit the violent TV shows or violent games to young children [22]. In addition, aggressive kids are less popular than unaggressive kids. Then, because they are not satisfied with their peer relationships now, they tend to spend more time watching the TV. The aggressive behaviors on TV make them believe that their behaviors are acceptable. Then they attempt to use this in their real life, which makes them more unpopular and drives them back to watching the violent TV. This is a bad circle for children who have aggressive behaviors [23].

There are some solutions to this problem. For example, some researchers proposed that when children watching a violent film, they asked aggressive children to feel the feelings of the victims in the film. Then boys do not show an increase in aggressive behaviors after watching the film, however, this solution does not apply to girls [24]. Obviously, it is necessary to take different measures to resolve the impact of media on boys and girls.

Watching violent film do have some influence on children's aggressive behaviors. It is important to discuss this topic because watching violent films will not only affect children's aggressive behaviors but also predict adults' future aggressive behaviors [25].

\section{Other factors and interaction among different factors}

Other interactions and factors still affect the form of aggressive behaviors. For example, genders. To be specific, boys and girls often show different forms of aggression. Boys tend to show more overt aggression and girls tend to show more relational aggression. This may because that relational aggression is significantly connected with maladjustment issues. For example, girls are more possible to engage in the psychological-adjustment problems, these problems make girls more 
engaged in relational aggression [26]. In addition, children from different cultures may have different forms of social acceptance. That is to say, victimized and aggressive children have different characteristics in different cultures. For example, studies run on 8 to 10 years old children find that shyness-sensitivity is significantly negatively correlated with the peer acceptance in Canada, whereas the Chinese sample found that shyness-sensitivity is significantly positively correlated with the peer acceptance [27]. In comparison, other researchers also propose that it might be biased to consider only one factor that produces aggression. It is now to shift our focus to the interaction of different factors. For example, by comparing Italian and American boys and girls, it is found that Italian boys display more overt aggression than girls, but American girls do not display more relational aggression than American boys. The researchers think that this may because Italian students are usually taught by three different teachers on one subject so that they don't know the students very well [28].

Therefore, it is not one single factor that produces children's aggression. It is different factors combine and interact with each other to produce children's aggressive behaviors.

\section{Summary and Suggestions}

Even though most research focuses on aggressive behaviors among adolescents, it is still important to consider children's aggressive behaviors at a small age. Because children's aggressive behaviors at a very small age may predict their tendency to be aggressive in the future [15, 25]. It is also important to consider the ages of children. Because children may under different developmental periods in different time frames, they may exhibit different kinds of aggressive behaviors because of different reasons. Therefore, psychologists should do research on young children at a specific age and this research may only apply to children of a specific age [28].

Furthermore, it is important to consider different factors when we talk about children's aggression. For example, cultures may shape different parenting behaviors or ways of teaching, and those factors, in turn, produce children's behaviors [28]. Children's behaviors will also influence how parents and teachers treat them [16-17]. In addition, bullying will hurt victims' psychological health and victims may display aggressive behaviors when they grow up [6,15]. Moreover, it is important to pay attention to the interaction among all the reasons for being aggressive because it is rarely that only a single reason could cause the serious aggressive behaviors of children. So, due to the complexity of reasons on children's aggression behaviors, in order to solve this problem, it is important for parents, teachers, and society to work hard together on reducing children's aggressive behaviors.

\section{References}

[1] Pang, J. S., Ang, R. P., Kom, D. M., Tan, S. H. and Chiang, A. Q. (2013) Patterns of reactive and proactive aggression in young adolescents in Singapore. Social Development, 22(4), 794-812.

[2] Babore, A., Carlucci, L., Cataldi, F., Phares, V. and Trumello, C. (2017) Aggressive behavior in adolescence: Links with self-esteem and parental emotional availability. European Psychiatry, 26(4), 2043-2043.

[3] Lorber, M. F., Del Vecchio, T. and Slep, A. S. (2018) The development of individual physically aggressive behaviors from infancy to toddlerhood. Developmental Psychology, 54(4), 601-612.

[4] Ellis, W. E. and Zarbatany, L. (2007) Peer group status as a moderator of group influence on children's deviant, aggressive, and prosocial behavior. Child Development, 78(4), 1240-1254.

[5] De la Torre-Cruz, M. J., García-Linares, M. C. and Casanova-Arias, P. F. (2014) Relationship between parenting styles and aggressiveness in adolescents. Electronic Journal Of Research In Educational Psychology, 12(1), 147-169.

[6] Perren, S. and Alsaker, F. D. (2006) Social behavior and peer relationships of victims, bullyvictims, and bullies in kindergarten. Journal of child psychology and psychiatry, 47(1), 45-57. 
[7] Coyne, S. M., Archer, J. and Eslea, M. (2006) "We're not friends anymore! Unless...”: The frequency and harmfulness of indirect, relational, and social aggression. Aggressive Behavior, 32, 294-307.

[8] Lorber, M. F., Del Vecchio, T. and Slep, A. S. (2018). The development of individual physically aggressive behaviors from infancy to toddlerhood. Developmental Psychology, 54(4), 601-612.

[9] Moffitt, T. E., Caspi, A., Dickson, N., Silva, P. and Stanton, W. (1996) Childhood-onset versus adolescent-onset antisocial conduct problems in males: Natural history from ages 3-18 years. Development and Psychopathology, 8, 399-424.

[10] Chen, F. R. and Raine, A. (2017) Effects of harsh parenting and positive parenting practices on youth aggressive behavior: The moderating role of early pubertal timing. Aggressive Behavior, 44(1).

[11] Mendez, M., Durtschi, J., Neppl, T. K. and Stith, S. M. (2016) Corporal punishment and externalizing behaviors in toddlers: The moderating role of positive and harsh parenting. Journal Of Family Psychology, 30(8), 887-895.

[12] Burt, S. A., Klahr, A. M., Neale, M. C. and Klump, K. L. (2013) Maternal warmth and directiveness jointly moderate the etiology of childhood conduct problems. Journal Of Child Psychology And Psychiatry, 54(10), 1030-1037.

[13] Hipwell, A., Keenan, K., Kasza, K., Loeber, R., Stouthamer-Loeber, M. and Bean, T. (2008) Reciprocal influences between girls' conduct problems and depression, and parental punishment and warmth: A six-year prospective analysis. Journal Of Abnormal Child Psychology, 36(5), 663-677.

[14] Llorca, A., Cristina Richaud, M. and Malonda, E. (2017) Parenting, peer relationships, academic self-efficacy, and academic achievement: Direct and mediating effects. Frontiers In Psychology, 8.

[15] Ladd, G. W. (2006) Peer rejection, aggressive or withdrawn behavior, and psychological maladjustment from ages 5 to 12: An examination of four predictive models. Child development, 77(4), 822-846.

[16] Chang, L. (2003) Variable effects of children's aggression, social withdrawal, and prosocial leadership as functions of teacher beliefs and behaviors. Child development, 74(2), 535-548.

[17] Scarr, S. and McCartney, K. (1983) How people make their own environments: A theory of genotype: environment effects. Child Development, 54(2), 424-435.

[18] McCarthy, R. J. (2017) Experiencing instigations and trait aggression contribute to harsh parenting behaviors. Psychological Reports, 120(6), 1078-1095.

[19] Ellis, B. J. and Boyce, W. T. (2008) Biological sensitivity to context. Current Directions in Psychological Science, 17(3), 183-187.

[20] Hicks, D. J. (1965) Imitation and retention of film-mediated aggressive peer and adult models. Journal of Personality and Social Psychology, 2(1), 97.

[21] Wilson, B. J. (2008) Media and children's aggression, fear, and altruism. The future of children, 18(1), 87-118.

[22] Anderson, C. A., Berkowitz, L., Donnerstein, E., Huesmann, L. R., Johnson, J. D., Linz, D. and Wartella, E. (2003) The influence of media violence on youth. Psychological science in the public interest, 4(3), 81-110.

[23] Eron, L. D. (1982) Parent-child interaction, television violence, and aggression of children. American Psychologist, 37(2), 197.

[24] Nathanson, A. I. and Cantor, J. (2000) Reducing the aggression-promoting effect of violent cartoons by increasing children's fictional involvement with the victim: A study of active mediation. 
Journal of Broadcasting \& Electronic Media, 44(1), 125-142.

[25] Huesmann, L. R., Moise-Titus, J., Podolski, C. L.and Eron, L. D. (2003) Longitudinal relations between children's exposure to TV violence and their aggressive and violent behavior in young adulthood: 1977-1992. Developmental psychology, 39(2), 201.

[26] Crick, N. R. and Grotpeter, J. K. (1995) Relational aggression, gender, and social-psychological adjustment. Child development, 710-722.

[27] Chen, X., Rubin, K. H. and Sun, Y. (1992) Social reputation and peer relationships in Chines3 and Canadian children: A cross-cultural study. Child Development, 63(6), 1336-1343.

[28] Tomada, G. and Schneider, B. H. (1997) Relational aggression, gender, and peer acceptance: Invariance across culture, stability over time, and concordance among informants. Developmental psychology, 33(4), 601. 